\title{
Ricardo Palma y el mundo de la política. Siglos XIX - XX
}

Por Carlos Alberto Pérez Garay 
Licenciado en Historia por la Universidad Nacional Mayor de San Marcos. Realiza labores docentes en la Universidad Ricardo Palma. Especialista en temas de historia política, intelectual y literaria. 
A lo largo de la historia del Perú republicano, los intelectuales han logrado convertirse, en numerosas oportunidades, en los principales protagonistas del mundo de la política. En efecto, guiados por una actitud ambivalente, tanto de adhesión y oposición hacia el poder político, los llamados "sujetos de ideas", han logrado incursionar, desde diferentes experiencias y espacios, en diversas prácticas políticas. Algunos de ellos intervendrán, de manera indirecta, como observadores críticos de la situación política del país (a través de la prensa oficialista o de oposición y su producción intelectual: libros, artículos, etc.), mientras que otros se convertirán directamente en actores políticos, siendo líderes, asesores, candidatos, funcionarios o ideólogos, es decir, justificadores de proyectos políticos ${ }^{1}$. Así, pues, entre los intelectuales peruanos que llegaron a involucrarse en el terreno de la política, podemos encontrar como ejemplo a José María Pando, Felipe Pardo y Aliaga y Fernando Casós, en el siglo XIX, y José de la Riva Agüero y Víctor Andrés Belaunde en el siglo XX, quienes, dejando un poco de lado su labor intelectual, lograran alcanzar cierto protagonismo en esta difícil y complicada actividad.

Sin embargo, a pesar de sus denodados esfuerzos, ninguno de estos intelectuales alcanzó a sentir la política con tanta

l Una revisión de los diversos y complejos aspectos de la relación entre los intelectuales y política en el Perú a lo largo de la historia podemos encontrarla en el libro de Osmar Gonzales. La academia y el ágora. En torno a intelectuales y política en el Perú. Lima: Fondo Editorial UNMSM - IPEDHP, 2010. 
pasión e intensidad como sí lo hizo el propio Ricardo Palma. En efecto, el autor de las Tradiciones logró entregarse a esta actividad de la misma forma como se entregó a la actividad literaria, derrochando en ella su espíritu de servicio, energía inquebrantable y defensa de sus ideales.

Los primeros encuentros de Palma con la política se remontan al año de 1839. Contaba con apenas seis años de edad cuando su padre, Pedro Palma, partidario del general Santa Cruz logró contarle algunas noticias políticas del país. Debido a la influencia de su progenitor, Palma demostró tempranamente su simpatía política por el creador de la Confederación Perú-boliviana. En su tradición "Una visita al mariscal Santa Cruz", el escritor recordó que una noche de enero de 1839 divisó, desde el balcón de su casa de la Calle del Rastro de San Francisco, a un grupo de oficiales santacrucistas que venían a veloz cabalgata. Excitada su imaginación por las noticias de su padre, Palma exclamó iViva Santa Cruz!, grito infantil que marcara su debut político ${ }^{2}$.

Disuelta la Confederación, su padre quizás pudo haberle comentado algunas noticias sobre el nuevo presidente, el general Agustín Gamarra, a quien vio luego “aclamado en la Plaza de

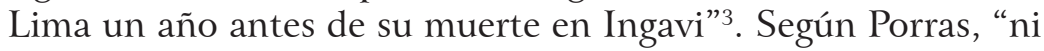
don Pedro ni su hijo debieron ser partidarios de Gamarra, ya que el tradicionista dijo de este que fue el primero que implantó en el Perú cátedra de anarquía y bochinche"

A medida que su infancia transcurría entre juegos y travesuras en los jardines y plazas de la ciudad, el inquieto niño alcanzó a

2 Oviedo. Genio y Figura de Ricardo Palma. p. 35

3 Tr. "Una visita al Mariscal Santa Cruz". TPC. p. 1419.

4 Porras. "De la autobiografía a la biografía de Palma”. p. 15, dato recogido de la Tr. "La conspiración de capitanes". 
escuchar, en esos espacios públicos, una serie de bandos sobre asuntos de policía y gobierno, los cuales eran leídos al público por un pregonero mayor. Dichos bandos fueron el entretenimiento de Palma y poco a poco, a tan corta edad, logró familiarizarse con los temas de interés público y, sobre todo, con los asuntos de carácter político ${ }^{5}$.

En esos lejanos días de su "niñez traviesa”, Palma también llegó a conocer -casi de cerca- a muchos de nuestros gobernantes del período de la anarquía militar; nombres como los generales Francisco de Vidal, Juan Crisóstomo Torrico, Manuel Ignacio de Vivanco y civiles como los doctores Manuel Menéndez (conocido por el pueblo con el apodo de el "chancaquero") y Justo Figuerola (quien oyendo una manifestación reunida fuera de su casa, solicitándole su renuncia, arrojó su banda por el balcón); ellos desfilaron ante los ojos del niño y futuro escritor 6 . Al parecer, Palma simpatizó con Torrico "por su ilustración y cultura y hasta por razones de provincialismo", y además porque era "el ídolo de la juventud limeña, a la que también pertenecía, pues aún no alcanzaba a contar con treinta y seis años"7. La misma simpatía debió de inspirarle por aquella época el Supremo Director del Perú, el general Vivanco, tal vez arrastrado por una corriente propia de esos años debido a que él mismo anotó en una de sus Tradiciones que "de moda estuvo ser vivanquista en los primeros tiempos del Directorio". Palma, quien confesó también en otra de sus Tradiciones haber sido devoto del general Vivanco ${ }^{9}$, pudo haberse rendido a sus cortos nueve años ante la imagen deslumbrante del caudillo militar, quien con su galante

5 Tr. "Pepe Bandos". TPC. p. 544.

6 Tr. "Una visita al Mariscal...”. TPC. p. 1419.

7 Tr. "La soga arrastra”. TPC. p. 1098.

8 Tr. "Seis por seis son treinta y seis". TPC. p. 1058.

9 Tr. "Gazapos Oficiales”. TPC. p. 1514 
figura, inteligencia y elegancia literaria, logró atraer a un gran número de admiradores ${ }^{10}$.

Sin embargo, meses después de este suceso, los sentimientos del pequeño Ricardo sobre Vivanco sufrirían un duro golpe, ya que el 22 de julio de 1844 el llamado Supremo Director y sus tropas fueron derrotados en la batalla de Carmen Alto, por obra del general Castilla, quien puso fin a su gobierno. Vencido y exiliado su caudillo, el inquieto niño y estudiante del Colegio de Noel, al parecer no vio con mucha agrado al general Castilla, quien fue elegido Presidente en 1845. No obstante, como resultado de los logros iniciales del gobierno, la actitud de Palma sobre Castilla empezó a cambiar, llegándole a tener gran simpatía. Así, pues, el futuro escritor seguirá de cerca la labor del presidente en la capital llegando a conocerlo muy bien, tal es así que lo describirá años después en sus Tradiciones como un personaje socarrón, intuitivo, criollo, obstinado y valiente ${ }^{11}$. Incluso, alcanzó a encontrarlo en cierta ocasión fuera de Lima, en el muelle del Callao, en la estación veraniega de 1847. Palma, junto a otros muchachos de su edad, llegaron a rodear a Castilla, logrando escucharlo hablar y sentir su enojo ante la repentina llegada del "godo Maroto" 12 .

Sin embargo, poco después de aquel anecdótico episodio la simpatía de Palma hacia Castilla empezó a desaparecer. ¿Qué había sucedido? La respuesta es simple. Por medio de las noticias obtenidas de la prensa y de sus amigos, el joven colegial se enteró de las numerosas críticas dirigidas al presidente,

10 Antes que Vivanco, similar admiración llegó a sentir Palma en sus remotos años de niñez por la figura y personalidad del general Agustín Lerzundi, a quien conoció en persona. Tr. "Las mentiras de Lerzundi". TPC. p. 1093 - 1094.

11 Augusto Tamayo Vargas. Apuntes para un estudio de la literatura peruana. Lima: 1947, p. 203. Véase también, del mismo autor, el artículo: "El Mariscal Castilla y los románticos”, en Revista del Instituto Libertador Ramón Castilla. (Lima, 1955); I, 2, p. 191.

12 “El Godo Maroto”. TPC. pp. $1113-1114$. 
las cuales se debían a su marcado autoritarismo. Ante dicha situación, Palma dejará de ser simpatizante de Castilla. Pero no todo quedará ahí. Contagiado, como muchos jóvenes, por los ideales del liberalismo, su espíritu beligerante empezará a relucir. Palma pasará de ser un espectador pasivo de la política peruana para convertirse en un activo opositor del gobierno de Castilla.

Así, en 1848, año en que se afilia al movimiento romántico de la "Bohemia limeña", el joven estudiante y un grupo de "bohemios" se vieron en la necesidad de expresar abiertamente sus propios comentarios políticos. Para dicho efecto, fundaron en Lima en setiembre de 1848, un semanario político de oposición, llamado El Diablo. Palma, quien por entonces contaba con tan solo quince años, hizo en esta publicación vinculada a El Zurriago sus primeros pininos de periodista político ${ }^{13}$.

En esta labor, Palma utilizará una poderosa arma de combate: la sátira ${ }^{14}$, género literario con el cual se hallaba estrechamente familiarizado, producto de la constante lectura de las famosas Capelladas de Fray Gerundio y de los Diálogos del padre Anselmo y su lego Tifas ${ }^{15}$. Precisamente, por medio de la sátira, el joven

13 Porras. "Palma Periodista". p. 6.

14 Escrita en prosa y en verso, la sátira fue en el siglo XIX la mejor arma para fustigar a los gobiernos. Porras ha señalado que "la sátira es la expresión de ese primer período de nuestra vida independiente, en el que los que no se sentían capaces de tomar un fusil para unirse a las revueltas enristraban la pluma y amenazaban a los gobiernos con la temible y risueña oposición de una hoja de papel". Raúl Porras Barrenechea. "La sátira en el Perú”, en Satíricos y costumbristas. Lima: Patronato del libro peruano, 1957, p. 13.

15 Modesto La Fuente y Zamalloa, cuyo seudónimo era Fray Gerundio, escribió sus famosas Capelladas "Periódico satírico de política y costumbres" (Madrid León, 1847-1843) en diecisiete volúmenes. Holguín. Tiempos de infancia... pp. 204-206. Los Diálogos del padre Anselmo y su lego Tifas, escritos por el Coronel Juan Espinosa, fueron unos artículos satíricos - políticos que aparecieron publicados en El Zurriago y en varios periódicos de la capital. Holguín ha señalado que los mencionados Diálogos de Espinosa fueron escritos bajo el modelo de las Capelladas. Ibíd. p. 206. Porras afirma que Espinosa "fue uno 
"bohemio" criticará a numerosos personajes del gobierno, así como también a personajes de la vida política y social del país.

Palma trabajó en El Diablo hasta diciembre de 1848. Al año siguiente, como muchos jóvenes de su edad, tendrá en mente proseguir estudios superiores. Así, pues, en 1849 , ingresa a cursar estudios de jurisprudencia en el Convictorio de San Carlos, dirigido por entonces por Bartolomé Herrera. Precisamente, mientras realizaba sus estudios, el novel escritor regresó a la labor periodística en un diario capitalino: El Correo Peruano, en donde tendrá oportunidad de compartir labores con destacadas figuras de la política nacional como Benito Laso, Francisco Javier Mariátegui y Francisco de Paula Gonzales Vigil, los cuales se convertirán en "sus primeros maestros de periodismo" 16 . Precisamente por aquel año, al iniciarse el proceso electoral peruano, Palma llegó a afiliarse -aunque no lograse votar- a la candidatura del general Vivanco, ejemplo de caudillo culto y ordenado que a muchos jóvenes llamaba la atención por su ilustración, refinamiento y condiciones de líder.

Sin embargo, las simpatías por el ex Supremo Director no duraron mucho tiempo. Vivanco fue derrotado en los comicios, siendo elegido presidente, el general Echenique. Encaramado en el poder en 1851, Echenique recibió el apoyo de muchos jóvenes, entre ellos los del propio Palma, quien en abierta actitud partidaria logró respaldar las acciones del gobierno a través de sus notas en El Correo Peruano. Tras el cierre de esta publicación, en agosto de 1851, el escritor limeño pasará a formar parte del equipo de redacción de El Correo del Perú. Según cuenta Palma, en este diario se ejercitó en el dominio de la prensa política,

de los primeros mentores políticos de los adolescentes de la época, entre ellos de Palma que le miraba como una especie de Dantón laico de la ortodoxia republicana en lucha con el militarismo". "Palma periodista". p. 6.

16 Ibíd. p. 551. 
siendo su principal guía su amigo de "Bohemia", Juan Sánchez Silva.

Tras su alejamiento de El Correo del Perú, Palma continuará su labor periodística en otros diarios de la capital, como El Intérprete del Pueblo, El Burro, El Mensajero y El Heraldo de Lima. En estas publicaciones, el escritor seguirá respaldando, las acciones del régimen de Echenique. Precisamente, en mérito de su apoyo al gobierno, el 16 de marzo de 1853, el Jefe de Estado y su ministro de Guerra, Juan Crisóstomo Torrico, lo nombran oficial $3^{\circ}$ del Cuerpo Político de la Armada. En este nombramiento, pesó mucho la influencia política de su amigo el doctor Miguel del Carpio, quien fue el protector de los jóvenes "bohemios".

$\mathrm{Al}$ ingresar a la marina Palma se dedicó a labores netamente burocráticas, tanto en las islas Chincha como en el puerto del Callao, el principal centro de operaciones de la Escuadra. Sin embargo, como atento observador de la política peruana, el joven pudo llegar a advertir la ola de críticas contra el gobierno de Echenique, a raíz del derroche económico de la consolidación.

Tras la caída de Echenique, en enero de 1855, la política siguió siendo el centro de atención del joven marino. Efectivamente, en los pocos momentos libres que disponía Palma se dará tiempo para intercambiar opiniones con sus amigos "bohemios", Márquez, Cisneros, Corpancho y Salaverry, sobre la actualidad política del país ${ }^{17}$. Uno de los temas que captó su atención fue la

17 Al parecer Palma lanzó desde las páginas de El Heraldo de Lima, algunas críticas al gobierno de Castilla y a los diputados de la Convención Nacional. En sus recuerdos de La Bohemia de mi tiempo, Palma señaló: "Hasta esa mesalina llamada política daba, de vez en cuando temas para nuestras burlas, Márquez, Corpancho, Cisneros, Camacho, Salaverry, Heros, el que esto suscribe y otros, establecieron una subasta pública de pollinos, y en verso se formulaban las propuestas y las adjudicaciones al mejor postor y el público reía a todo reír. 
incidencia de la Convención Nacional, que entró en funciones en julio de 1855. Fue tanto el interés de Palma por estas sesiones que se hizo presente en el local congresal, logrando presenciar y escuchar los acalorados debates de los diputados José Simeón Tejeda, José Gálvez Egúsquiza e Ignacio Escudero, en torno a temas como la eliminación del Consejo de Estado, el sufragio universal y la tolerancia de cultos $^{18}$.

Precisamente, por ese año Palma se aproximó al máximo representante del liberalismo peruano del siglo XIX: Don José Gálvez, llegando a convertirse en uno de sus más fervientes partidarios. No obstante, seguirá la expectativa de la promulgación de la nueva Carta Magna, la cual fue finalmente aprobada por Castilla el 19 de octubre. La promulgación de esta nueva Constitución originó una ola de protestas en algunas ciudades del país. Así, el 31 de octubre de 1856, a pocos días de promulgada la Constitución, estalló en Arequipa una revolución en favor del general Vivanco. Este movimiento, rápidamente fue secundado por varios grupos armados, entre ellos la oficialidad del vapor "Loa", embarcación en donde servía el joven marino Ricardo Palma.

Obligado por orden de sus superiores, y también porque estaba convencido de que el proyecto político de Vivanco era lo más conveniente para el destino del país, Palma logró prestar su apoyo a la causa revolucionaria, llegando a participar en varias expediciones navales en el norte. No obstante su apoyo, su

iCuánto ingenioso y cáustico varapalo a ministros y diputados! iCuánto gasto de agudeza epigramática!” TPC. p. 1306.

18 Palma pudo estar presente en esta asamblea. En su Tr. "El chocolate de los jesuitas". TPC. pp. 631 - 632, el escritor limeño hizo alusión aque estuvo presente en el Congreso de la República, escuchando hablar a Santiago Távara, autor de La historia de los partidos, quien era diputado por Jaén entre 1856 y 1858. Sobre los debates de la Convención puede verse el artículo de José Gálvez Barrenechea. "El Liberalismo Doctrinario". En Fanal (Lima, 1955) V. X, $\mathrm{N}^{\mathrm{o}} 43$, pp. $18-23$. 
aventura vivanquista solo durara cinco meses, tiempo en el cual logró defender y apoyar al caudillo militar.

Tras la derrota de Vivanco, Palma fue separado temporalmente, por el gobierno, del Cuerpo de la Armada, motivo por el cual volverá al periodismo. En 1858 y 1859, formó parte del equipo de redacción de dos importantes diarios: El Liberal y La Zamacueca Política. En este ultimo diario, Palma escribió las semblanzas de los diputados y senadores del Congreso Extraordinario de 1858, que fueron una serie de noventa y siete notas anónimas alusivas al desempeño de los representantes de ese Cuerpo Legislativo ${ }^{19}$. En ellas, el escritor empleará su inconfundible y original estilo satírico-zumbón.

Sin embargo, las ansias de Palma de seguir participando en la política activa lo llevaron a tomar mayor protagonismo. Así, a finales de noviembre de 1860 formó parte de un frustrado complot revolucionario, dirigido por José Gálvez contra el Presidente Castilla. Al descubrirse su participación el escritor fue intensamente buscado por la fuerza pública. Temeroso por su vida solicitó, junto a otros implicados, asilo político en la Legación de Chile, el cual le concedió la respectiva autorización para viajar al país del sur. El día 20 de diciembre el joven escritor se embarcó rumbo a Chile, llegando a Valparaíso en los primeros días de 1860. Durante su permanencia en esa ciudad, el escritor frecuentó los salones literarios y perteneció a la Sociedad Amigos de la Ilustración, colaborando en La Revista de Sudamérica de la cual llegó a ser redactor principal. Asimismo se vinculó con la logia masónica "Lautaro" y la sociedad "Unión Americana", institución que tenía como propósito la defensa

19 Tauro del Pino recopiló las Semblanzas de Palma, escritas en la Zamacueca Política, y las publicó en un folleto. Véase: Ricardo Palma. Semblanzas. Edición y Prólogo del Alberto Tauro del Pino. Lima: Librería Editorial Juan Mejía Baca, 1961. Véase también el comentario a las Semblanzas por J. Basadre. Historia de la República... V. 6. pp. 172- 173. 
de la independencia de América. Precisamente, en Valparaíso, Palma tendrá oportunidad de acercarse y entablar conversación con algunos políticos peruanos exiliados en Chile, como los ex presidentes Vivanco y Echenique a quienes había admirado años atrás. Según señala Riva Agüero, Palma "vivió con el general Echenique y le redactó un extenso manifiesto a pesar de su reciente disconformidad de ideas con este derrocado presidente conservador" 20 . Incluso llegó a intervenir en un debate público, a raíz de una alusión hecha por un orador chileno contra la política de Castilla, quien invadió Ecuador y ocupó el puerto de Guayaquil. Cuando en este debate se llegó a comparar al general Castilla con los dictadores Juan Manuel Rosas de Argentina y el doctor Francia de Paraguay, Palma defendió al presidente peruano, quien no tenía punto de comparación con aquellos siniestros personajes ${ }^{21}$.

En octubre de 1862, como consecuencia de la ley de amnistía otorgada por el presidente San Román, el escritor regresa al Perú. A su llegada retorna a la labor periodística en El Mercurio, dirigido por Manuel Atanasio Fuentes. Fallecido San Román, en mayo de 1863, Palma pondrá su pluma al servicio del gobierno del nuevo presidente, el general Pezet. Precisamente, por su apoyo partidario, el joven periodista fue nombrado por el Jefe de Estado, en julio de 1864, como Cónsul en el Pará (Brasil). A fines de ese mes, Palma emprendió su viaje con destino a Europa, a fin de que un vapor lo llevase directamente a territorio brasileño para tomar posesión de ese cargo diplomático. Sin embargo, cuestiones personales y administrativas le impedirían ejercer tan importante labor. Ante tal decepción decidió retornar al país, llegando a desembarcar en Paita en la quincena de mayo

20 Riva Agüero. “En la muerte de don Ricardo Palma”. p. 373. El manifiesto de Echenique fue publicado como: Los hechos: exposición que dirige a los pueblos del Perú. José Rufino Echenique. Valparaíso: Imprenta del Universo de Hel Finam, 1861.

21 Ibíd. p. 374. 
de 1865. Al llegar a ese puerto Palma tuvo acercamiento con las fuerzas del coronel José Balta, cuyo movimiento se había extendido en el norte peruano. Chiclayo, Trujillo, Cajamarca y Huaraz fueron los principales reductos de las huestes baltistas. $\mathrm{Al}$ parecer, fue el propio Palma quien se acercó a Balta, expresándole su incondicional apoyo y colaboración, frente a lo cual el rebelde coronel se mostró agradecido ${ }^{22}$. El encuentro entre estos dos hombres, dio origen a una buena amistad, convirtiéndose el escritor en uno de los hombres de confianza del caudillo norteño.

El 6 de noviembre de 1865, las tropas revolucionarias del norte y del sur ingresaron a Lima deponiendo al presidente Pezet. El nuevo gobierno, al mando del coronel Prado premió la participación del escritor nombrándolo con un puesto burocrático en el Ministerio de Guerra y Marina, que estaba dirigido por entonces por su antiguo líder político, José Gálvez. Sin embargo, tras la muerte de éste, en el combate del 2 de mayo, los animos de Palma de seguir con su labor burocrática empezaron a decaer. Ante tal situación solicitó un cambio de funciones, lo cual se hizo efectivo y nombrado profesor en el Colegio Naval Militar, en donde enseñará los cursos de Historia Militar y Derecho Marítimo. Precisamente, estando abocado a la labor docente Palma se dará tiempo para cuestionar los actos de la "Dictadura" de Prado y expresar su apoyo al coronel Balta a través del diario El Constitucional, en donde compartió labores con su amigo Carlos Augusto Salaverry.

El gobierno, enterado de las críticas de El Constitucional ordenó la inmediata clausura del diario y la detención de sus principales

$22 \mathrm{Al}$ parecer Palma pudo haber conocido a Balta muchos años antes, debido a que este último era un ferviente militar echeniquista, llegando a luchar contra el ejército de Castilla en la batalla de la Palma el 5 de enero de 1855. 
redactores. Palma será conducido, a fines de diciembre de 1866, a la prisión de Casa Matas en el Callao para luego ser enviado, en los primeros días de enero de 1867, con destino a Panamá. $\mathrm{Al}$ marchar al exilio panameño, la nave que lo conducía hizo un alto en el puerto de Paita, oportunidad que fue aprovechado por el escritor y otros prisioneros políticos, que viajaban junto a él, para escapar. Al regresar a Lima, a fines de mayo, Palma volvió al periodismo, formando parte del equipo de redacción de La Campana, semanario de corte satírico y de oposición al gobierno de $\mathrm{Prado}^{23}$. Palma será en este semanario el principal redactor y lo acompañarán en esa labor Benito Neto, Juan De los Heros y Justiniano de Zubiría. En este periódico Palma escribirá diversos comentarios políticos, exhibiendo, como siempre, su original e inconfundible sello satírico. Entre sus artículos más destacados podemos mencionar sus conocidas Semblanzas, en donde retratará a los representantes del Congreso Constituyente de $1867^{24}$.

Palma se alejó de La Campana a mediados de agosto. Dejará la pluma periodística para empuñar el fusil. En efecto, el escritor viajó al norte del país para unirse a la revolución que encabezaba su amigo el coronel José Balta, quien fue nombrado en Trujillo como Jefe Superior Político y Militar del Norte. Palma fue designado por Balta como su secretario privado, encargándose de redactar sus manifiestos y proclamas, así como también de aconsejarlo en diversos temas políticos.

23 El título de La Campana responde al clima adverso que se vivía en el país, por un decreto del Secretario de Gobierno, José María Quimper, de reglamentar los toques de las campanas de las iglesias.

24 En julio de 1867 Palma mandó a editar en un folleto sus Semblanzas de un Campanero, que aparecieron en el periódico La Campana (Publicación número 4 y número 5 del 7 y 21 de julio de 1867). Alberto Tauro del Pino en 1961 publicó nuevamente el folleto acompañado de las Semblanzas que hizo Palma sobre el Congreso de 1858 que aparecieron en La Zamacueca Política. Ver: Ricardo Palma. Semblanzas. 
Al lado del caudillo norteño el escritor atravesó una serie de inconvenientes propios de la campaña militar. Al lomo de bestia, y a veces a pie, recorrió junto a otros revolucionarios diversos lugares, como Trujillo, Otuzco y Cajamarca, logrando batirse con valentía frente a las tropas del gobierno. Inclusive llegó a participar, tal como lo cuenta en su tradición "La Conga", en la defensa de la ciudad de Chiclayo, en donde los 150 hombres harapientos, mal armados, del ejército de Balta, resistieron por espacio de un mes a las tropas enemigas, calculadas en más de 1000 hombres, los cuales llegaron a rendirse el 6 de enero de 1868.

Triunfante la revolución, Palma se dirigió a Lima con el fin de impulsar la candidatura presidencial de Balta. Como su secretario personal y hombre de confianza, la labor del escritor consistió en organizar a los distintos clubes políticos que apoyaban la candidatura de Balta en Lima ${ }^{25}$. Según Fernando Casós, en su novela Los hombres de bien, Palma (cuyo alter ego era Edgardo Dátiles) asistió el día 18 de marzo, a la proclamación de la candidatura presidencial de Balta en los baños de Piedra Liza. En dicho acto, el secretario del caudillo norteño se dirigió a la multitud, pronunciando un corto discurso en donde expresó sus sentimientos de admiración hacia su líder.

Celebradas las elecciones generales el mes de abril, el Congreso declaró como ganador al coronel Balta. Al enterarse de la noticia, el nuevo Jefe de Estado nombró como secretario de la Presidencia al escritor limeño, quien también fue elegido como senador por el Departamento de Loreto. Al asumir sus funciones en el despacho presidencial, Palma logró estar en permanente diálogo con el Jefe de Estado, el cual le manifestó,

25 El Comercio. Lima, sábado 29 de febrero de 1868. "Comunicados”. Carta de Palma aceptando la candidatura de la Sociedad Constitucional Eleccionaria. Firmada el 26 de febrero. 
en varias oportunidades, su intensa preocupación por los destinos del país. Como secretario de Balta, Palma se ocupó de programar la agenda del Presidente de la República ${ }^{26}$. Asimismo, se encargó de otras labores, tales como atender a distintas personalidades que deseaban entrevistarse con el Jefe de Estado, escribir diversos oficios de carácter gubernamental, redactar discursos para las ceremonias oficiales del presidente, entre otros escritos ${ }^{27}$. Por otro lado, su labor parlamentaria fue destacada, llegando a participar en cuatro legislaturas entre 1868 y 1873. Bastaría leer sus discursos parlamentarios y proyectos de ley para darse cuenta de sus convicciones democráticas, anticlericales y antimilitaristas, los cuales iban bien acordes con su pensamiento liberal. En sus cuatro años como secretario del Presidente y senador de la República, el escritor se involucró plenamente con la política. Sin embargo, su intensa pasión por esta actividad pronto llegaría a su fin. El día 26 de julio de 1872 su amigo el presidente Balta fue asesinado cobardemente por obra de los hermanos Gutiérrez. Aquel trágico episodio marcaria profundamente la labor política del escritor, al punto de pensar abandonar esta difícil y complicada actividad. A pesar de ello, continuará, durante el gobierno de Pardo, asistiendo al Senado al haberse prorrogado sus funciones con motivo de

26 Una definición de dicho cargo para esa época la da Francisco García Calderón: "Secretario Privado. Con este nombre suele designarse al que lleva la correspondencia particular del Presidente de la República. Este secretario es empleado de la nación. Y como no está considerado en el presupuesto general, será rentado con los fondos propios del Presidente que lo ocupa”, en Francisco García Calderón. Diccionario de la Legislación Peruana. Lima: Imprenta del Estado por Eusebio Aranda, 1862. T. II (E - Z), p. 1017.

27 Los elementos civiles que tuvieron actuación en la vida política peruana durante los primeros cincuenta años de la República fueron denominados por Basadre como "validos" o "censores". La función de los "validos" variaba según la idiosincrasia de los caudillos; por lo general les correspondía redactar, aconsejar, legislar. Redactaban las proclamas, los oficios, los decretos, los mensajes. Aconsejaban los cuartelazos, los apresamientos, las posturas políticas, etc. Basadre. Perú: problema y posibilidad. p. 50. Palma fue un "valido". 
la instalación urgente de la nueva Legislatura Extraordinaria de 1872. Precisamente, siendo senador en esa legislatura, el escritor recibió incesantes críticas por parte de sus enemigos civilistas, quienes llegaron a acusarlo por su vinculación con el anterior gobierno. Profundamente afectado, Palma comprendió que ese era el precio que debía pagar por haber incursionado en el complicado terreno de la política. No obstante, siguió asistiendo a sus labores parlamentarias hasta el 18 de abril de 1873, día en que terminó la legislatura. Al finalizar sus funciones Palma se retirará de la actividad política militante para dedicarse a tiempo completo a seguir escribiendo sus Tradiciones, las cuales le depararán el prestigio literario. Ahora bien, en resumidas cuentas, "la política le restó fuerzas como literato; pero fue el caldo de cultivo de sus relatos; le suministró la emoción del Perú y le garantizó cierta estabilidad pecuniaria, pues cuando se retiró a sus cuarteles de invierno (1873) pudo regodearse a sus anchas con la literatura y la historia y vivir de su pluma y de sus pensiones de cesantía" ${ }^{28}$. $\mathrm{Al}$ abandonar esta difícil y complicada actividad se perdió a un político, pero se ganó a un literato para el orgullo del Perú y América.

Sin embargo, a pesar de su retiro de la política activa el escritor limeño, en su condición de ciudadano e intelectual, se dará tiempo para emitir, a través de las paginas de El Nacional y La Patria, algunos comentarios sobre los gobiernos de Manuel Pardo y Mariano Ignacio Prado. Poco después, al iniciarse la Guerra con Chile, Palma expresó su apoyo partidario a Nicolás de Piérola. Precisamente, cuando el caudillo civil instaló su gobierno en Ayacucho fue Palma la persona que alcanzó a contarle acerca de los actos del gobierno de García Calderón. Incluso, cuando el Califa convocó al nuevo Congreso en esa

28 Julio Díaz Falconí. Ricardo Palma, Personaje de si mismo. Lima: Facultad de Letras y Ciencias Humanas de la Universidad Nacional Mayor de San Marcos, s. a. Separata de Sphinx, 1967, p. 35. 
ciudad, el escritor mostró su interés por participar en esa Asamblea aunque no pudo lograr su cometido.

A pesar de ello, Palma seguirá colaborando con Piérola. Así, pues, en 1882, en plena ocupación chilena, ambos formaron parte de la junta directiva del Partido Nacional Reconstituyente, partido que fue creado para contribuir a la unificación nacional como medio para enfrentar el desastre de la guerra. Palma estará en este partido hasta agosto de 1884. Tras su salida, se dedicará completamente a su labor literaria y a sus funciones como Director de la Biblioteca Nacional. No obstante, a pesar de sus múltiples ocupaciones, el escritor seguirá pendiente del panorama político del país, por lo que en algunas oportunidades se dará tiempo para emitir, en algunas de sus cartas a amigos escritores del Perú e Hispanoamérica, algunos juicios sobre los actos del gobierno. Precisamente, en el tiempo que estuvo como director de la Biblioteca Nacional Palma empezó a tener una postura política moderada o conservadora ${ }^{29}$. Como muchos peruanos, estaba cansado de los contantes golpes de estado y los derramamientos de sangre, por ello llegó a mostrarse inclinado hacia el sostenimiento del orden democrático y el respeto a las leyes.

En 1912, tras alejarse de la Biblioteca Nacional el escritor, en su casa de Miraflores, continuó con su atención a las incidencias políticas del país a través de los diarios que le proporcionaba su hija y secretaria personal Angélica Palma y también por las noticias que le comentaban sus amigos visitantes. A pesar de que su salud andaba algo resquebrajada él se dará tiempo para verter sus opiniones del acontecer nacional en las cartas que dirigía a sus amigos en el extranjero. Así, el $1^{\circ}$ de enero de 1919 el octogenario hombre de letras escribió a su joven amigo José

29 Víctor Andrés Belaunde. "Palma Político", en Sociedad Amigos de Palma. Ricardo Palma. 1833 [-] 1933. Lima. Cía. de Impresiones y Publicidad. 1934, p. 66. 
Gálvez Barrenechea, en ese momento cónsul en Barcelona, una carta que contenía sus últimos comentarios políticos ${ }^{30}$. En ella, le expresaba su preocupación por la campaña presidencial entre Augusto. B. Leguía y Antero Aspíllaga, los principales protagonistas de la contienda.

El día 6 de octubre de 1919, a tan solo seis días de la proclamación de Leguía como nuevo Presidente Constitucional de la República, Palma falleció en su residencia de Miraflores. Su muerte fue muy sentida en el Perú y en varios países de América. De haber vivido unos años más de seguro hubiera enfilado sus críticas al presidente y a su gobierno de la Patria Nueva, así como también hubiese comentado los principales sucesos políticos del Perú y del mundo.

30 Palma a José Gálvez Barrenechea. Miraflores, $1^{\circ}$ de enero de 1919. en "Antología de José Gálvez...”. p. 283. 